\title{
Residual strains around cold worked holes from statistical view
}

\author{
E. Pooladi ${ }^{\mathrm{a}^{*}}$ and Kh. Farhangdoost $\mathrm{a}^{\mathrm{a}}$
}

${ }^{a}$ Department of Mechanical Engineering, Ferdowsi University of Mashhad, Mashhad, Iran

\begin{tabular}{l}
\hline A R T I C L E I N F O \\
\hline Article history: \\
Received September 20, 2013 \\
Received in Revised form \\
October, 14, 2013 \\
Accepted 22 January 2014 \\
Available online \\
24 January 2014 \\
\hline Keywords: \\
Cold work \\
Experimental study \\
Residual strain \\
Residual stress \\
Statistical distribution
\end{tabular}

\section{A B S T R A C T}

Cold working a hole decreases tendency of fatigue crack initiation and growth near the hole. It is due to creation of some compressive tangential residual stresses around the hole. But there are many uncertainties which affect the residual strain and residual stress field. In fact these uncertainties lead to have scatter in the test results and considering the residual strains and residual stresses as random variables. In this paper strains recorded by strain gages mounted around the hole during cold working process in seven pieces specimens, were analyzed by statistical tests and stochastic properties of mentioned random variables were obtained using SPSS software. The residual strains have been also distributed by normal probability distribution function.

\section{Introduction}

Cold working process, which increases fatigue life of components, consists of pushing a mandrel with greater diameter into the hole with smaller size; named loading step, and then removing it; which is called unloading step. During the loading step, an annular plastic zone is created around the hole which is surrounded by the remaining elastic region and during the unloading step, the elastic region compresses the plastic zone and some residual stresses will be remained around the hole. In fact, compressive tangential residual stresses around the cold-worked hole is usefull for delaying crack initiation or decreasing fatigue crack growth rate. Obtaining residual stress field is an important object for design and predicting the main events in the component life such as maintenance time, reliability and so on. Some researchers have performed analytical solutions and have compared the results with finite element method (FEM), such as Stacy and Webster (1988), Walin (1993), Pavier et. al. (1999), Jahed et al. (2000), Zhao et al.(2003), Pinho et al. (2005), Matos et al. (2005), Hojjati and

\footnotetext{
* Corresponding author.

E-mail addresses: ehsanpb@yahoo.com (E.Pooladi) 
Hassani (2007), Nigrelli and Pasta (2008), Su et. al. (2008), Ayatollahi and Arian Nik (2009), Maximov et al. (2009), Reese et al. (2009) and Yan et al. (2012). Gopalakrishna et al. (2010) have considered the effect of two kinds of the cold working process at different expansion levels on the fatigue life. They have used strain gages mounted around the hole. Others have also suggested experimental procedure for measuring and obtaining the residual stress field.

It should be noted that most of the available studies have considered the residual stresses resulted by cold working in deterministic state. However, there are many uncertainties that are affected the residual stress and material behavior around the cold worked hole which lead to have scatter in results in same conditions. Therefore, all of the analytical relations and even experimental results; such as the X-ray diffraction, neutron diffraction, strain gages, etc., just introduced a mean and average of the mentioned scatter in an optimistic manner. As Sobczyk and Trebicki (2004) underlined following statement stated by Nelson (1982) before "An assessment of predictive ability of the superposition approach must be done with caution, since its success or lake thereof depends on accurate knowledge of the initial residual stress field, which is often a source of considerable uncertainty in itself". Of course few authors were considered residual stresses as random variables too, such as Millwater et al. (2007) which introduced a normal distribution function for residual stress.

The most important parameters which lead to have scatter results in the residual stress field due to the cold working are: i) material properties and metallurgical processing, ii) producing process and iii) cold working process, which cannot be separated the contribution of each ones.

i) Variation of microstructure features such as size, number and arrangement, anisotropy properties of grains, etc. lead to considering material properties as random variables, as Farhangdoost and Rahnama (2011) have stated before.

ii) Producing processes are quality controlled with some engineering restrictions such as tolerances and surface quality. In fact these restrictions are used for overcome to the drawback of manufacturer for non-uniformity of their process. Since it is impossible to manufacture quantities of machine parts with exactly the same dimensions, systems have been devised to tolerate small dimensional variations of the mating parts without sacrificing their proper functioning. When a component has been manufactured in a special tolerance range, the concerned dimension is a random variable with normal probability function with some special famous values, named mean, variance and standard deviation. It should be noted that the tolerance range is equal to 6 times of standard deviation, named six-sigma rule.

iii) Cold working process: In the loading step of the cold working process, the mandrel size is greater than the hole size and interference creates due to shrink fit. When two components mate together by shrink fit, the difference between the shaft and the hole sizes; interference; is a probability function which obtained by subtracting the hole size probability function and the shaft size probability function. The expansion level defined in cold working process; which strictly depends on interference value; is one reason for uncertainty. In fact cold working by an exact expansion value is impossible and should be devised with caution. The mandrel has been suggested to be rigid than the hole, but reality some elastic deformation of the mandrel which is disregarded in analytical solution and depends on assembling condition, affects residual stress field. Also some other parameters such as lateral surface quality of the hole are the other uncertainty origins which are affected the residual stress field.

According to the above explanations, the residual stresses of cold working process, are random variables and have probability function. Consequently, statistical consideration of residual stresses 
plays an important role for taking all uncertainties into account, of course as stated before, it is impossible to set apart the contribution of each of parameters affected on residual stress. Measuring surface strains around the hole has been introduced as feature for residual stress filed, as Gopalakrishna et al (2010), Garcia-Granada et al. (2003) and Pooladi and Farhangdoost (2013) stated before.

In this research, an experimental study has been presented for obtaining the statistical properties of the residual strain around the cold-worked hole. Seven pieces specimens have been prepared and cold-worked, which some strain gages mounted on each one at a defined radius. During cold working, the strains are measured. For validation of experimental results, the strain measured by gage has been compared with finite element result.

Results showed scatter in measured strains which can be related to the residual stress filed. It should be noted that the all samples are completely similar to each other and produced with a same process and the mandrel prepared for cold working, is same for all holes as well. Also the condition of cold working test is same for all specimens. Therefore the scatter of results can be related to inherent statistical properties of residual stresses, explained above. Results showed that the residual strains were distributed by normal probability function. For statistical analyzing of results, SPSS software was used.

\section{Experimental procedure}

Specimens prepared from a rolled sheet material; 8mm thickness; made of Al2024-T351 (which is used frequently in aerospace industries) all in the longitudinal direction. Chemical properties of A12024-T351 are listed in Table 1.

Table1. Chemical properties of Al2024-T351

\begin{tabular}{lllllllllllllll}
\hline $\mathrm{Si}$ & $\mathrm{Fe}$ & $\mathrm{Cu}$ & $\mathrm{Mn}$ & $\mathrm{Mg}$ & $\mathrm{Zn}$ & $\mathrm{Ti}$ & $\mathrm{Cr}$ & $\mathrm{Ni}$ & $\mathrm{Pb}$ & $\mathrm{Sn}$ & $\mathrm{Ca}$ & $\mathrm{Sb}$ & $\mathrm{P}$ & $\mathrm{Al}$ \\
\hline 0.054 & 0.202 & 4.176 & 0.539 & 1.405 & 0.081 & 0.012 & 0.009 & 0.009 & 0.002 & 0.006 & 0.002 & 0.001 & 0.009 & $\mathrm{Remained}$ \\
\hline
\end{tabular}

Main mechanical properties are included of yielding $\left(\sigma_{\mathrm{y}}\right)$ at $367.88 \mathrm{MPa}$, elastic moduless $(E)$ of $77.5 \mathrm{GPa}$ and ultimate strength $\left(\sigma_{\mathrm{ult}}\right)$ of $457 \mathrm{MPa}$. It is evident that the mentioned values are mean of a distribution of random variables.

As stated before, seven specimens have been made of Al2024-T351 plate with $8 \mathrm{~mm}$ thickness and a radial hole, $5^{ \pm 0.01} \mathrm{~mm}$ in diameter, was created by drilling and then reaming. It should be reminded that producing process such as production temperature, humidity, speed of drilling and reaming and also quality of tools in machining are all the same and is not differed from one specimen to another. The mandrel was made in tapered shape with maximum diameter $5.2^{ \pm 0.01} \mathrm{~mm}$ which creates 4\% nominal expansion. Figs. 1 and 2 show the shop drawing of the plate and the mandrel. The mandrel was made of SPK steel alloy (which is suitable for ramrod and piston, etc.) with $E=210 \mathrm{GPa}$ and Poisson's ratio $(v)$ equals to 0.3 . On all specimens, a $\pm 350 \Omega$ resistance strain gages was mounted radially at $r=10.5 \mathrm{~mm}$ and $\theta=0^{\circ}$ (from the center of hole). Fig. 3 shows a specimen with gage mounted on it, during cold working process. Lubrication between the mandrel and the hole was used for minimizing friction effect.

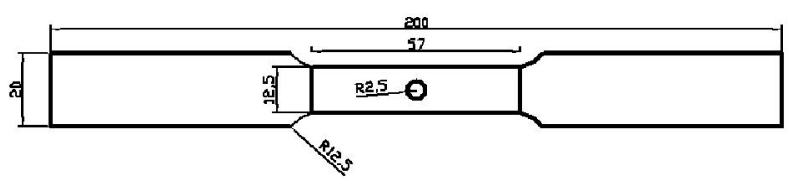

Fig. 1. Shopping drawing of plate

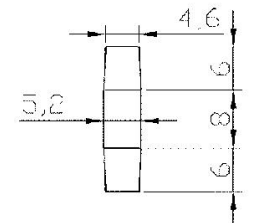

Fig. 2. Tapered mandrel 
Cold working process was performed by universal ZWICK Z250. The mandrel pushed into the hole with a constant speed $(2 \mathrm{~mm} / \mathrm{min})$. During the cold working process, the strains recorded by a logger based on Wheatstone bridge. As stated before, using the strain values read by the gage and substitution into one of the analytical relationship leads to drive residual stress field.

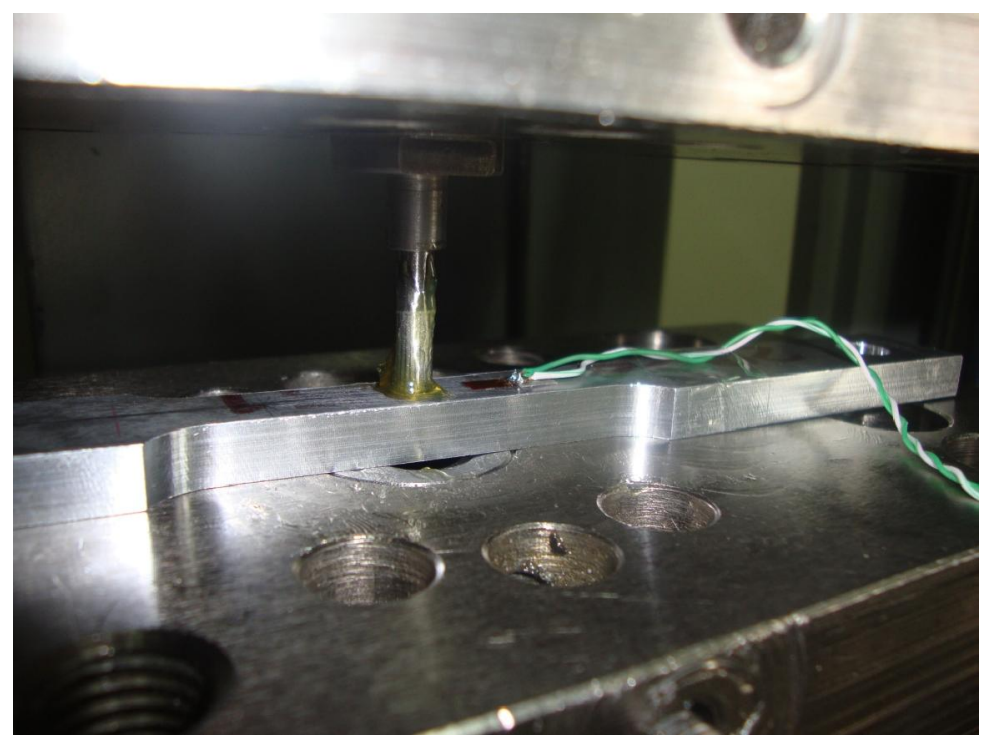

Fig. 3. Cold working process on specimen with mounted a gage at $r=10.5 \mathrm{~mm}$

\section{Results}

As stated before, surface strain around the hole at a defined radius, $r=10.5 \mathrm{~mm}$; was measured by the strain gage mounted on the specimens. Fig.4 shows variation of strain versus time of the cold working in one sample and FEM result which is verified the experimental procedure for measuring the strains.

Scatter of the strains in all specimens has been shown in Fig. 5 and scatter of pushing force on the mandrel during cold working has been shown in Fig .6. As predicted before, there is scatter in experimental results which are related to the inherent nature and mentioned origins of residual stresses. At the defined radius; $r=10.5 \mathrm{~mm}$; and same conditions in all tests, strains are distributed as random variables. Also the force acting on the mandrel for moving and removing into the hole is distributed with a probability function. Statistical analysis of the two mentioned sets of random variables has performed by SPSS15 software. Special points of process in all specimens have been taken into consideration.

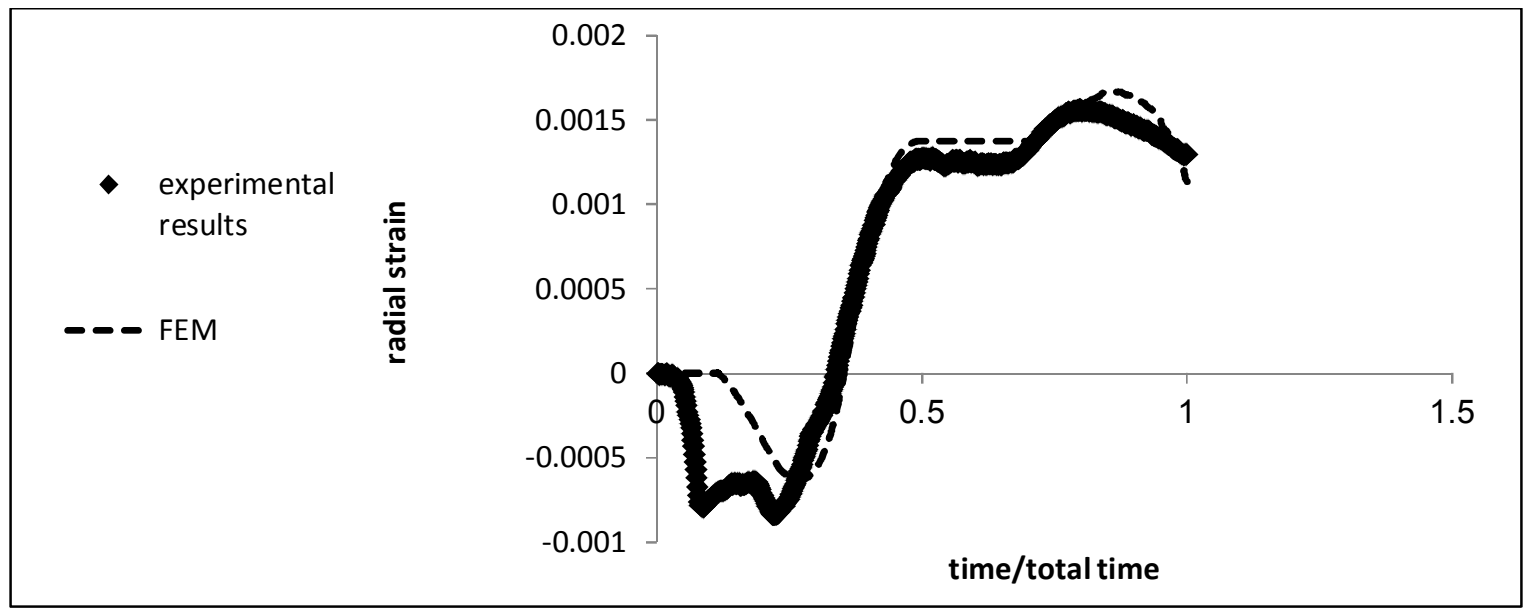

Fig. 4. Strain variations versus time change during cold working at $r=10.5 \mathrm{~mm}$ 


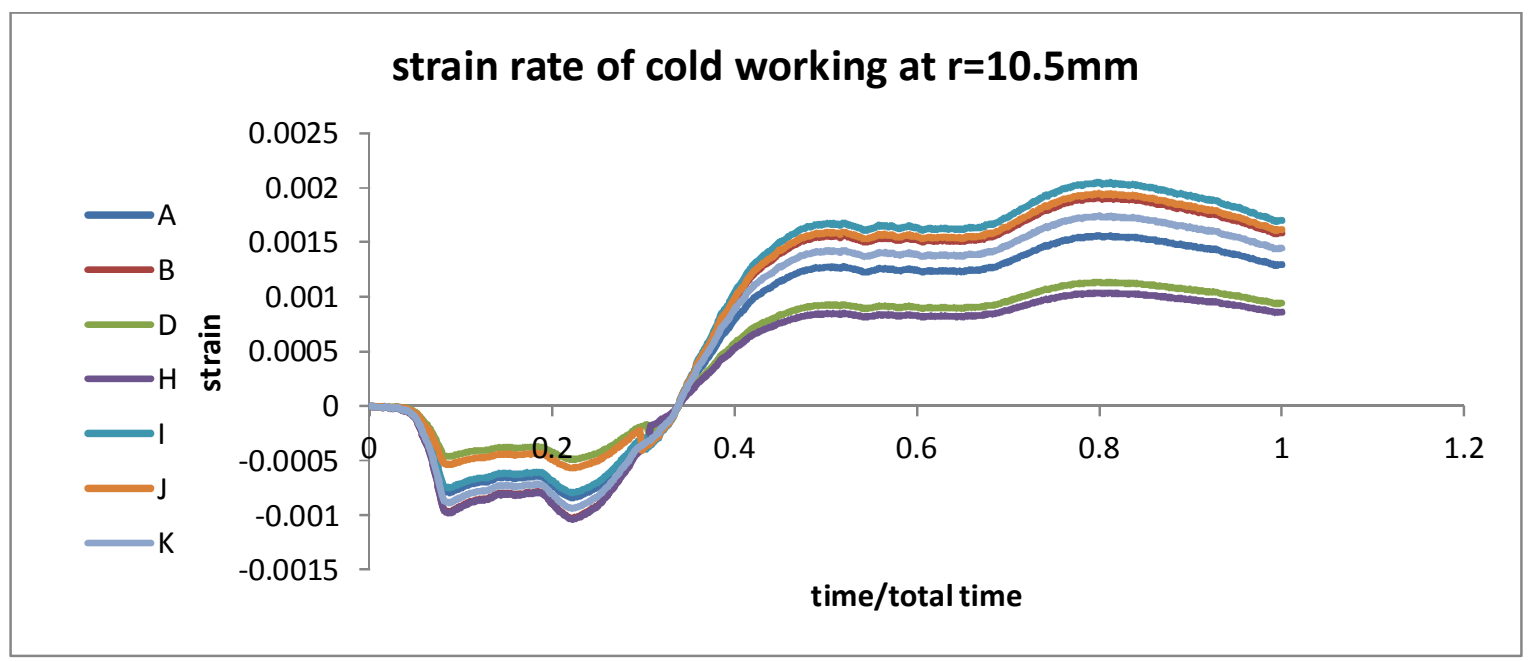

Fig. 5. Scatter of strain rate of various specimens during cold working for seven specimens (A to K) examined

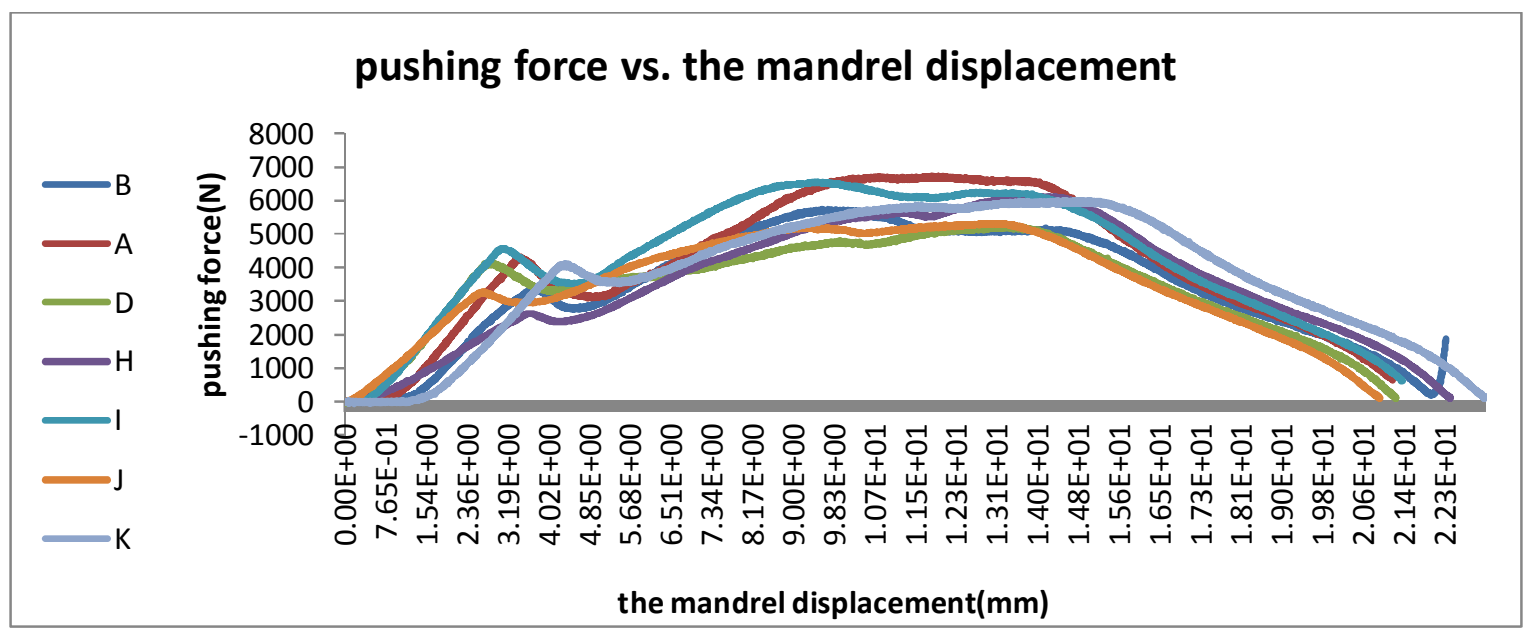

Fig. 6. Scatter of pushing force on the mandrell in the tested specimens

The statistical properties of the strains at the end of loading and the end of unloading step (i.e. residual strain; and the pushing force; at maximum stat) has been shown in Table2.

Table 2. Statistical descriptive of strain

\begin{tabular}{llllll}
\hline & Minimum & maximum & Mean & variance & Standard deviation \\
\hline Loading strain & 0.00082482 & 0.001628141 & 0.00129233 & $1.01837576 \mathrm{e}-007$ & 0.00031912 \\
Residual strain & 0.000861534 & 0.001700623 & 0.001349859 & $1.11107611848 \mathrm{e}-007$ & 0.00033333 \\
Maximum Pushing force acting on the mandrel(N) & 5231.99 & 6724.32 & 5953.117 & 322167.6285905 & 567.5981224339 \\
\hline
\end{tabular}

The probability of the above random variables has been checked with P-P plot statistic test in normal state. In the P-P plot test, the coincidence of normal probability distribution function (bisector of $1^{\text {st }}$ and $3^{\text {rd }}$ zone in plane) with the test results is criterion for specifying whether test results distributed in normal probability function or not.

Also some other statistic tests such as one-sample Kolmogorov-Sminrov can be used. The feature is used for being true or not the hypothesis (characterization the normal distribution function) in Kolmogorov-Sminrov test is named P-Value (2-tailed sig.) which should be greater than 0.05 (acceptable error level in statistical tests), as the greater P-value and the nearer to 1, the more strongly our hypothesis (here, normal distribution of random variables) will be true. The P-P plots of strains have been shown in Fig.7 and Fig. 8. 


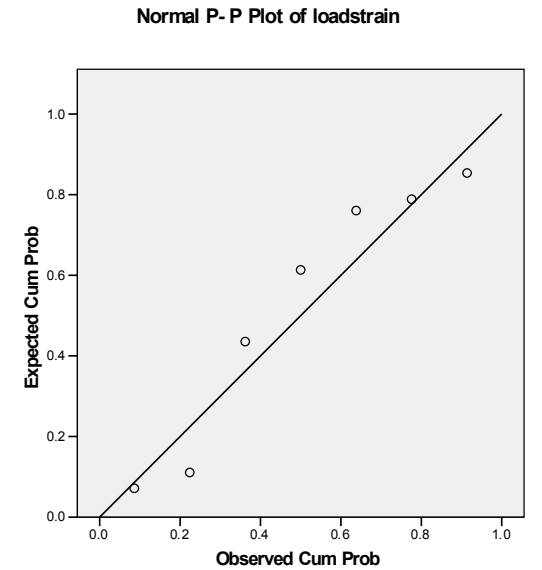

Fig. 7. The P-P plot of loading strains

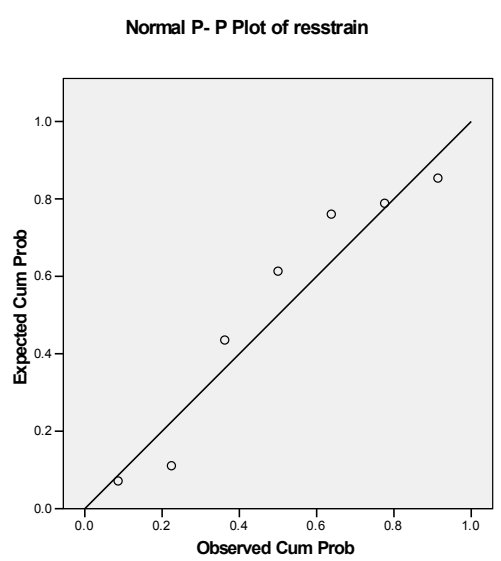

Fig. 8. The P-P plot of residual strains

Also the results of Kolmogorov-Sminrov for the strains have been shown in Tables 3 and 4. The P-P plot and Kolmogorov-Sminrov analysing results for the pushing force applied on the mandrel have been shown in Fig. 9 and Table 5, respectively.

Table 3. One-Sample Kolmogorov-Smirnov Test for load strains

\begin{tabular}{lll}
\hline & & Load strain \\
\hline Normal Parameters(a,b) & Mean & 7 \\
& Std. Deviation & .0012923303 \\
Most Extreme Differences & Absolute & .00031912000 \\
& Positive & .189 \\
& Negative & .175 \\
Kolmogorov-Smirnov Z & & -.189 \\
Asymp. Sig. (2-tailed) & & .500 \\
\hline a Test distribution is Normal. b Calculated from data. & & .964 \\
\hline
\end{tabular}

Table 4. One-Sample Kolmogorov-Smirnov Test for residual strains

\begin{tabular}{lll}
\hline & & Residual strain \\
\hline $\mathrm{N}$ & & 7 \\
Normal Parameters(a,b) & Mean & .0013498590 \\
& Std. Deviation & .00033332808 \\
Most Extreme Differences & Absolute & .189 \\
& Positive & .175 \\
& Negative & -.189 \\
Kolmogorov-Smirnov Z & & .500 \\
Asymp. Sig. (2-tailed) & & .964 \\
\hline
\end{tabular}

a Test distribution is Normal. b Calculated from data.

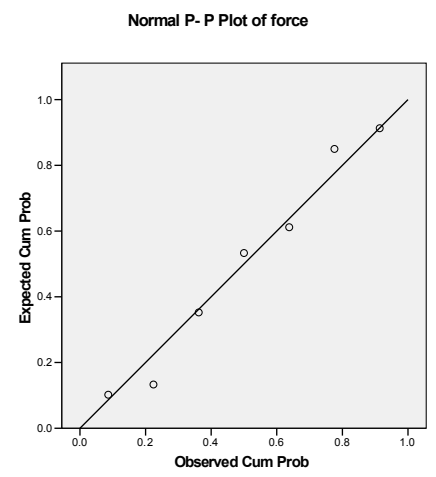

Fig. 9. The P-P plot of pushing force 
Table 5. One-Sample Kolmogorov-Smirnov Test for pushing force

\begin{tabular}{lll}
\hline & & force \\
\hline $\mathrm{N}$ & & 7 \\
Normal Parameters(a,b) & Mean & 5953.1171 \\
& Std. Deviation & 567.59812 \\
Most Extreme Differences & Absolute & .153 \\
& Positive & .153 \\
& Negative & -.136 \\
Kolmogorov-Smirnov Z & & .404 \\
Asymp. Sig. (2-tailed) & & .997 \\
\hline a Test distribution is Normal. & \\
b Calculated from data. & &
\end{tabular}

\section{Conclusions}

By studying the outcomes of the statistical analyzing of the experimental procedure and according to the scatter seen in the results, the below items should be noted:

5.1.There is a good agreement between the strain rate read by the gages and the FEM during the cold working process. Therefore the surface strain around the cold-worked hole is a good feature for determination of residual stress field. In this paper the scatter of the strains is taken into consideration. The scatter of the residual stresses around the cold-worked hole can be analyzed using similar method, which is the subject of author's research in the future.

5.2.Strains and residual strains around the cold-worked hole are in fact, the random variables and have statistical nature such as probability distribution function, mean, standard deviation and so on. As stated in the previous section, the probability distribution function for strains measured by the strain gages during the cold working process, according to the P-Value and the P-P plot is normal probability function.

5.3.The pushing force acting on the mandrel during the cold working procedure and function.

5.4. When the cold expansion level is the subject of discussion, a caution should be take into consideration about the uncertainties of the cold working procedure, inherently. According to the obtained scatter in the experimental results, cold working at a defined level; e.g. 4\%, leads to have variety of results in residual stress field. Some of the residual stress values at $4 \%$ expansion maybe deviated from the mean value as we can get it by other expansion levels, e.g. 3 or $5 \%$ expansion level. Therefore, considering the residual strains and consequently the residual stresses as probabilistic process, leads to take all of the affected uncertainties into consideration to obtain an accurate model for prediction residual stress field compared to other deterministic models.

\section{References}

Ayatollahi, M. R., \& Arian Nik, M. (2009). Edge distance effects on residual stress distribution around a cold expanded hole in Al 2024 alloy. Computational Materials Science, 45(4), 11341141.

De Matos, P. F. P., Moreira, P. M. G. P., Camanho, P. P., \& De Castro, P. M. S. T. (2005). Numerical simulation of cold working of rivet holes. Finite Elements in Analysis and Design, 41(9), 9891007.

Farhangdoost, K., \& Rahnama, S. (2011). Random Tessellation and its application at mechanics of microstructure. Journal of Solid and Fluid Mechanics, 1(1) 15-26.

Garcia-Granada, A. A., Smith, D. J., \& Pavier, M. J. (2000). A new procedure based on Sachs' boring for measuring non-axisymmetric residual stresses. International Journal of Mechanical Sciences, 42(6), 1027-1047.

Gopalakrishna, H. D., Narasimha Murthy, H. N., Krishna, M., Vinod, M. S., \& Suresh, A. V. (2010). Cold expansion of holes and resulting fatigue life enhancement and residual stresses in A1 2024 T3 
alloy-An experimental study. Engineering Failure Analysis, 17(2), 361-368.

Hojjati, M. H., \& Hassani, A. (2007). Theoretical and finite-element modeling of autofrettage process in strain-hardening thick-walled cylinders. International Journal of Pressure Vessels and Piping, 84(5), 310-319.

Jahed, H., Lambert, S. B., \& Dubey, R. N. (2000). Variable material property method in the analysis of cold-worked fastener holes. The Journal of Strain Analysis for Engineering Design, 35(2), 137 142.

Maximov, J. T., Duncheva, G. V., Ganev, N., \& Bakalova, T. N. (2009). The benefit from an adequate finite element simulation of the cold hole expansion process. Engineering Failure Analysis, 16(1), 503-511.

Millwater, H., Larsen, J., \& John, R. (2007). Effects of residual stresses on probabilistic lifing of engine disk materials. Materials Science and Engineering: A, 468, 129-136.

Nelson, D. V. (1982). Effects of residual stress on fatigue crack propagation. Residual Stress Effects in Fatigue, ASTM STP, 776, 172-194.

Nigrelli, V., \& Pasta, S. (2008). Finite-element simulation of residual stress induced by split-sleeve cold-expansion process of holes. Journal of Materials Processing Technology, 205(1), 290-296.

Pavier, M. J., Poussard, C. G. C., \& Smith, D. J. (1999). Effect of residual stress around cold worked holes on fracture under superimposed mechanical load. Engineering Fracture Mechanics, 63(6), 751-773.

Pinho, S. T., Martins, H. B., Camanho, P. P., Santare, M. H., \& De Castro, P. M. S. T. (2005). Residual stress field and reduction of stress intensity factors in cold-worked holes. Theoretical and Applied Fracture Mechanics, 44(2), 168-177.

Pooladi, E. \& Farhangdoost, Kh. (2013), A new practical-Analytical method to determine residual stresses around cold-worked hole based on measure residual strains, International Journal of Advances and Trends in Engineering Materials and Their Applications, 1(1), 47-52.

Reese, E. D., Dowson, A. L., \& Jones, T. G. (2009). The Variable Expansion Process-a New Cost Efficient Method for Cold Working Fastener Holes in Aluminium Aircraft Structures. In ICAF 2009, Bridging the Gap between Theory and Operational Practice (pp. 1275-1284). Springer Netherlands.

Stacey, A., \& Webster, G. A. (1988). Determination of residual stress distributions in autofrettaged tubing. International Journal of Pressure Vessels and Piping, 31(3), 205-220.

Sobczyk, K., \& Trebicki, J. (2004). Fatigue crack growth in random residual stresses. International Journal of Fatigue, 26(11), 1179-1187.

Su, M., Amrouche, A., Mesmacque, G., \& Benseddiq, N. (2008). Numerical study of double cold expansion of the hole at crack tip and the influence on the residual stresses field. Computational Materials Science, 41(3), 350-355.

Wanlin, G. (1993). Elastic-plastic analysis of a finite sheet with a cold-worked hole. Engineering Fracture Mechanics, 46(3), 465-472.

Yan, W. Z., Wang, X. S., Gao, H. S., \& Yue, Z. F. (2012). Effect of split sleeve cold expansion on cracking behaviors of titanium alloy TC4 holes. Engineering Fracture Mechanics, 88, 79-89.

Zhao, W., Seshadri, R., \& Dubey R.N., (2003), On thick-walled cylinder under internal pressure, Journal of Pressure Vessel Technology, 125, 267-273. 